\title{
Structural and chemical homogeneity of chalcogenide glass prepared by melt- rocking
}

Cite as: J. Chem. Phys. 150, 014505 (2019); https://doi.org/10.1063/1.5054704

Submitted: 02 September 2018 . Accepted: 13 December 2018. Published Online: 07 January 2019

Pierre Lucas (D), Garrett J. Coleman, Sabyasachi Sen (D), Shuo Cui, Yann Guimond, Laurent Calvez, Catherine Boussard-Pledel, Bruno Bureau, and Johann Troles

\section{ARTICLES YOU MAY BE INTERESTED IN}

Transformations of body-centered cubic crystals composed of hard or soft spheres to liquids or face-centered cubic crystals

The Journal of Chemical Physics 150, 014504 (2019); https://doi.org/10.1063/1.5059358

Calculation of the interfacial tension of the graphene-water interaction by molecular simulations

The Journal of Chemical Physics 150, 014703 (2019); https://doi.org/10.1063/1.5048576

Revisiting the Stokes-Einstein relation without a hydrodynamic diameter

The Journal of Chemical Physics 150, 021101 (2019); https://doi.org/10.1063/1.5080662

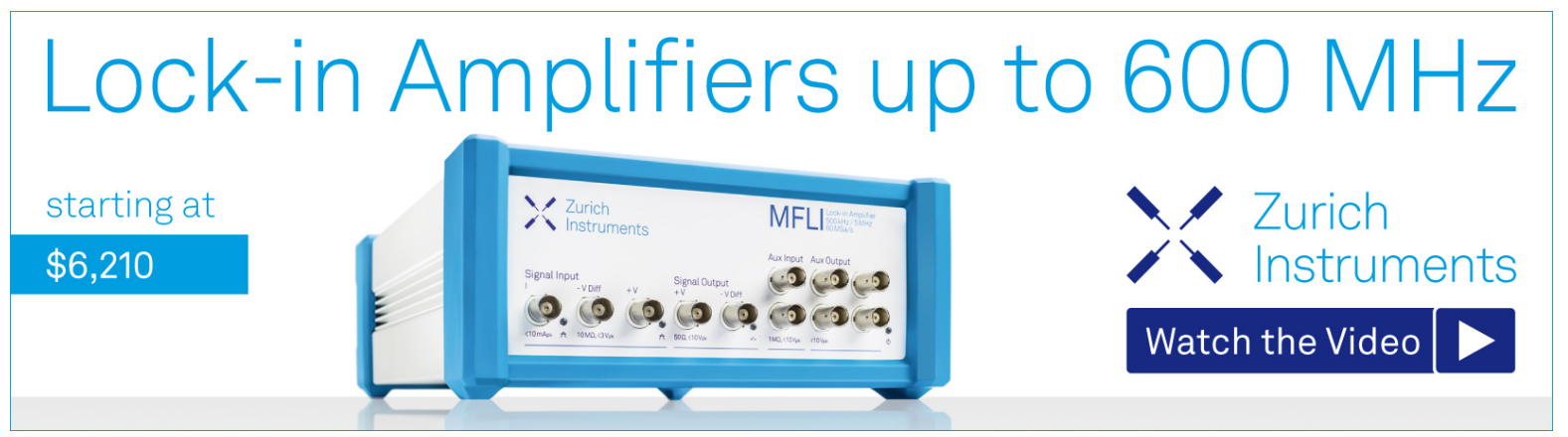

J. Chem. Phys. 150, 014505 (2019); https://doi.org/10.1063/1.5054704 


\title{
Structural and chemical homogeneity of chalcogenide glass prepared by melt-rocking
}

Cite as: J. Chem. Phys. 150, 014505 (2019); doi: 10.1063/1.5054704

Submitted: 2 September 2018 - Accepted: 13 December 2018 • Published Online: 7 January 2019

\section{(1) 『}

Pierre Lucas, ${ }^{1, a)}$ (D) Garrett J. Coleman, ${ }^{1}$ Sabyasachi Sen, ${ }^{2}$ (D) Shuo Cui,, ${ }^{1, b)}$ Yann Guimond, ${ }^{3}$ Laurent Calvez, ${ }^{4}$ Catherine Boussard-Pledel, ${ }^{4}$ Bruno Bureau, ${ }^{4}$ and Johann Troles ${ }^{4}$

\author{
AFFILIATIONS \\ ${ }^{1}$ Department of Materials Science and Engineering, University of Arizona, Tucson, Arizona 85721, USA \\ ${ }^{2}$ Division of Materials Science, University of California, Davis, California 95616, USA \\ ${ }^{3}$ Umicore IR Glass, ZA du Boulais, Acigne 35960, France \\ ¿Univ Rennes, CNRS, ISCR (Institut des Sciences Chimiques de Rennes)_UMR 6226, F-35000 Rennes, France
}

\begin{abstract}
a) Author to whom correspondence should be addressed: pierre@email.arizona.edu

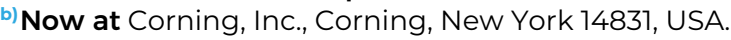

\begin{abstract}
The chemical and structural homogeneity of selenide glasses produced by mechanical homogenization of the melt in a rocking furnace is investigated by Raman and Energy Dispersive Spectroscopy (EDS). Both techniques demonstrate that the glass is macroscopically homogeneous along the entire length of a $6 \mathrm{~cm}$ rod. EDS imaging performed over four orders of magnitude in scale further confirms that the glass is homogeneous down to the sub-micron scale. An estimate of the diffusion coefficient from experimental viscosity data shows that the diffusion length is far larger than the resolution of EDS and therefore confirms that the glass is homogeneous at any length scale. In order to investigate a systematic mismatch in physical properties reported in the literature for glasses produced by extended static homogenization, two germanium selenide samples are produced under the same conditions except for the homogenization step: one in a rocking furnace for $10 \mathrm{~h}$ and the other in a static furnace for $192 \mathrm{~h}$. No difference in physical properties is found between the two glasses. The properties of an ultra-high purity glass are also found to be identical. The origin of the systematic deviation reported in the literature for germanium selenide glasses is therefore still unknown, but the present results demonstrate that homogeneity or dryness does not have a significant contribution in contrast to previous suggestions. The implications of glass homogeneity for technological applications and industrial production are discussed.
\end{abstract}

Published under license by AIP Publishing. https://doi.org/1 0.1 063/1.5054704

\section{INTRODUCTION}

Chalcogenide glasses have been the subject of considerable applied and fundamental research due to their importance as optical materials as well as their interest as modeling testbeds for topological constraint theories. From the technological point of view, amorphous chalcogenides are key materials for the design of complex infrared optics such as optical fibers, ${ }^{1}$ molded lenses, ${ }^{2}$ or films, ${ }^{3}$ but they have also found growing interest in the field of microelectronics such as non-volatile memories ${ }^{4}$ and flexible sensors. ${ }^{5}$ In this respect, an increasing number of commercial sources of amorphous chalcogenides have emerged including advanced optics and raw materials. ${ }^{6-10}$

From the fundamental point of view, chalcogenide glasses are of much interest due to their covalent network structure which lends itself well to constraint counting principles and 
has been the basis for the development of topological theories. ${ }^{1-14}$ Indeed, similar electronegativity of the component elements leads to strong covalent bonding schemes where each atom follows Mott's 8-N rule. In this scheme, each atom generates a well-defined number of bonds determined by its valence. This permits the enumeration of topological constraints including bond and angular constraints which controls the rigidity of the glassy network and is believed to help predict some of its physical properties.

A large number of studies have been performed over the years to investigate possible correlations between structure, physical properties, and topological predictions in chalcogenide glass systems. ${ }^{12,14-19}$ While some success has been achieved, an increasing body of conflicting results has also been reported with difficulties in reproducing certain findings. ${ }^{20-22}$ As pointed out in a review of the Ge-Se system, ${ }^{20}$ the source of the discrepancy appears to be mainly attributed to an unusual synthesis method involving static homogenization of the melt over extended periods of time. ${ }^{23-28}$ Yet, a brief survey of the literature indicates that chalcogenide glasses have been synthesized by melt-rocking for more than fifty years ${ }^{14,22,29-38}$ and that they are currently produced industrially in the same manner. ${ }^{39,40}$ The melt-rocking method has been adopted by the chalcogenide glass community early on when it was recognized that convection considerably reduces synthesis time by facilitating melt homogenization. The need for mechanical convection to achieve melt homogenization was reported as far back as 1959.41 Nevertheless, several reports have recently suggested that melt homogenization should instead be performed statically by natural diffusion over time periods as long as 17 days. ${ }^{23,27}$ It was further claimed that chalcogenide glasses prepared by meltrocking are instead structurally inhomogeneous and exhibit unpredictable and unreliable physical properties. ${ }^{26,27}$ Despite reports indicating that glasses synthesized by both methods behave identically, ${ }^{42}$ the inhomogeneity claim has been echoed in subsequent studies ${ }^{43,44}$ and is a source of increasing confusion in the field. If these claims are correct, they are of tremendous significance since they cast doubt over five decades of chalcogenide glass research. In this study, we therefore perform a thorough and systematic investigation of structural and chemical homogeneity in a selenide glass to address this issue. We then discuss melt homogenization from the point of view of viscous flow and diffusivity, and show that our findings are consistent with data obtained from industry as well as observations from technological application of chalcogenide glasses.

\section{EXPERIMENTAL}

\section{A. Glass synthesis}

An arsenic selenide glass rod of composition $\mathrm{As}_{25} \mathrm{Se}_{75}$ corresponding to the lowest fragility index reported in Ref. 27 was synthesized using the rock-melting method. A glass rod of mass $18 \mathrm{~g}$ was produced by introducing $6 \mathrm{~N}$ purity As and Se elements in a low-OH silica ampoule of diameter $8 \mathrm{~mm}$ previously washed with $\mathrm{HF}$ and ultrapure water, and baked at
$800{ }^{\circ} \mathrm{C}$. The ampoule was then brought to a $10^{-6}$ Torr vacuum and flame sealed with a hydrogen/oxygen torch. The ampoule was then inserted in a rocking furnace and heated to $750{ }^{\circ} \mathrm{C}$ at a rate of $5^{\circ} \mathrm{C} / \mathrm{min}$ and kept there for $10 \mathrm{~h}$. The rocking furnace tipping angle was $45^{\circ}$, and the rocking frequency was 6 oscillations/min. The furnace temperature was subsequently cooled to $500{ }^{\circ} \mathrm{C}$, and the ampoule was quenched in water. The ampoule was then immediately transferred to a furnace for annealing at $10{ }^{\circ} \mathrm{C}$ below $\mathrm{T}_{g}$. A glass rod of approximately $6 \mathrm{~cm}$ long was removed from the ampoule and polished on one side for analysis using $0.05 \mu \mathrm{m}$ alumina suspension as the final polishing step (Fig. 1).

Two germanium selenide samples of composition $\mathrm{GeSe}_{4}$ were also synthesized: one using the rock-melting method described above and the other using the static method described by Bhosle et al. ${ }^{23}$ for comparison. Both glasses were produced using the same batch of $6 \mathrm{~N}$ purity Ge and Se elements and the same low-OH silica tubes, $6 \mathrm{~mm}$ in diameter sealed under $10^{-6}$ Torr vacuum. The first glass was heated to $950{ }^{\circ} \mathrm{C}$ for $12 \mathrm{~h}$ in a rocking furnace as described above. The second glass was heated to $950^{\circ} \mathrm{C}$ for $192 \mathrm{~h}$ (8 days) in a static furnace as described in Ref. 23. Both glasses were quenched in water and annealed at $10{ }^{\circ} \mathrm{C}$ below $\mathrm{T}_{g}$ following the same procedure.

\section{B. Energy Dispersive Spectroscopy (EDS)}

Energy Dispersive Spectroscopy (EDS) was performed with a Hitachi S3400 scanning electron microscope at $30 \mathrm{keV}$.

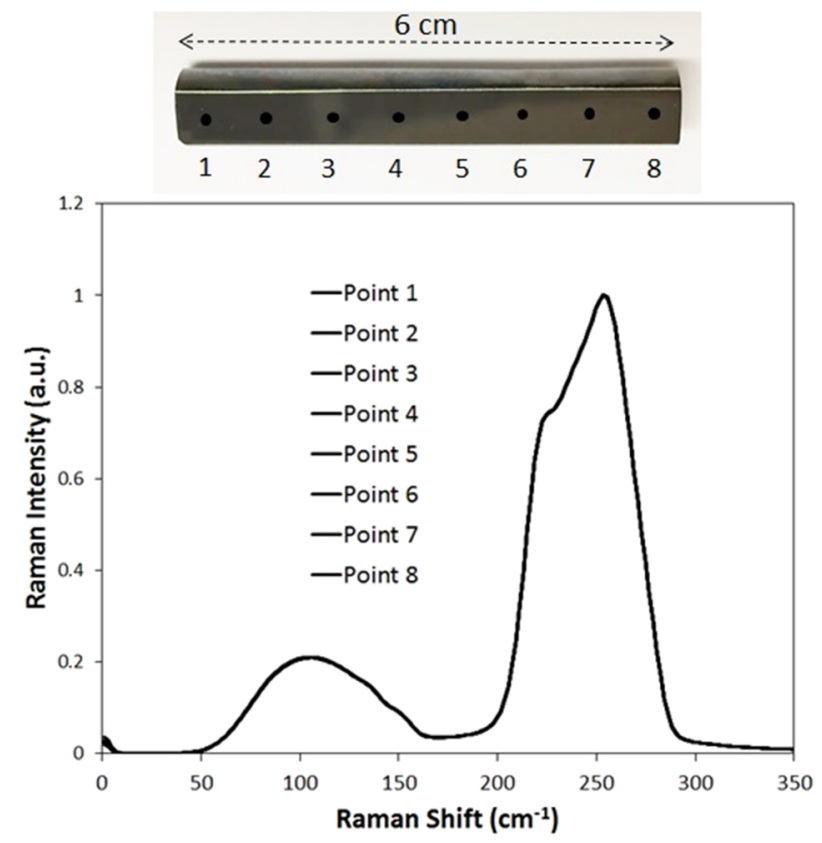

FIG. 1. Intensity-normalized unpolarized Raman spectra collected at eight points along a $6 \mathrm{~cm}$ long $\mathrm{As}_{25} \mathrm{Se}_{75}$ glass rod produced by melt-rocking. It is evident that all eight spectra are perfectly superimposable on one another, testifying to the structural and chemical homogeneity of the glass. 
Compositional analysis was performed along the entire length of the $\mathrm{As}_{25} \mathrm{Se}_{75}$ rod at about $1 \mathrm{~cm}$ intervals. EDS mapping images were then collected over 4 orders of magnitude in length scale ranging from $500 \mathrm{~nm}$ to $500 \mu \mathrm{m}$ and a collection time of 5 min for each point.

\section{Raman spectroscopy}

Raman spectroscopy was performed along the entire length of the $\mathrm{As}_{25} \mathrm{Se}_{75}$ rod at about $6 \mathrm{~mm}$ intervals. Unpolarized Raman spectra were collected at ambient temperature and in backscattering geometry using a Bruker RFS 100/S FourierTransform Raman spectrometer equipped with a Nd:YAG laser operating at $1064 \mathrm{~nm}$ and a liquid nitrogen cooled solid-state Ge detector. A laser power level of $50 \mathrm{~mW}$ was used, and spectra were collected using a resolution of $2 \mathrm{~cm}^{-1}$. Approximately 100 scans were collected and averaged to obtain each Raman spectrum. The low photon energy and the low power level, used to collect the Raman spectra, permitted us to avoid any photostructural damage during data collection.

\section{Density}

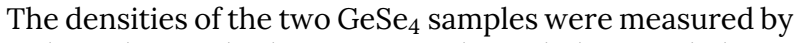
the Archimedes method using a Mettler Toledo XS64 balance with absolute ethanol as the displacement liquid at ambient temperature. Each measurement was repeated 6 times, and both samples were measured back to back to avoid any change in environmental conditions. The temperature was monitored continuously during the whole set of measurements.

\section{RESULTS}

\section{A. Structural and chemical homogeneity of glasses produced by melt-rocking}

In order to test the chemical and structural homogeneity of glasses produced by mechanical agitation, an $\mathrm{As}_{25} \mathrm{Se}_{75} \mathrm{sam}$ ple was synthesized by melt-rocking for $10 \mathrm{~h}$ at $750{ }^{\circ} \mathrm{C}$. This composition was chosen because it has the lowest fragility index according to Ref. 27 and should therefore retain a high viscosity with increasing temperature comparative to other composition in the As-Se system. Its ability to homogenize should therefore constitute an upper bound in this system, although strictly speaking the absolute temperature dependence of the viscosity is also a function of $\mathrm{T}_{g}$ which also varies with composition.

The structural and compositional homogeneity was first characterized by Raman spectroscopy, as shown in Fig. 1. The Raman spectra are essentially indistinguishable along the 8 points across the length of the glass rod. As previously demonstrated, Raman spectroscopy is a sensitive probe of structural and chemical fluctuations in the As-Se system. ${ }^{45}$ Variations in composition or local structure would lead to changes in vibrational density that would be easily observable on the Raman spectra. This result therefore indicates that the glass rod produced by melt-rocking is macroscopically homogeneous along the entire length of the rod.
In order to provide a quantitative measure of compositional homogeneity, EDS was also performed along the length of the $\mathrm{As}_{25} \mathrm{Se}_{75}$ glass rod as shown in Fig. 2. The atomic ratio is found to be highly reproducible along the length of the glass rod and well within the measurement error. These data corroborate the Raman results and confirm that the glass rod is macroscopically homogeneous.

It was previously conjectured that agitation in a rocking furnace only fragments the melt into domains of different compositions; ${ }^{27}$ however, no experimental evidence was provided to inform on the potential length scale of these domains. In order to investigate the possible presence of compositional domains in the glass, EDS imaging was performed over 4 orders of magnitude in length scale. Figure 3 shows the As and Se compositional maps of the $\mathrm{As}_{25} \mathrm{Se}_{75}$ sample ranging from several millimeters to microns. The compositional imaging demonstrates that the glass is chemically homogeneous at every length scale and that no compositional domains are present even at the smaller scale. Furthermore, the compositional average over each map is identical at each length scale. These results further corroborate the previous Raman and EDS data and establish that melt-rocking for periods as short as $10 \mathrm{~h}$ yields homogeneous glasses at all length scales for samples of a few grams.

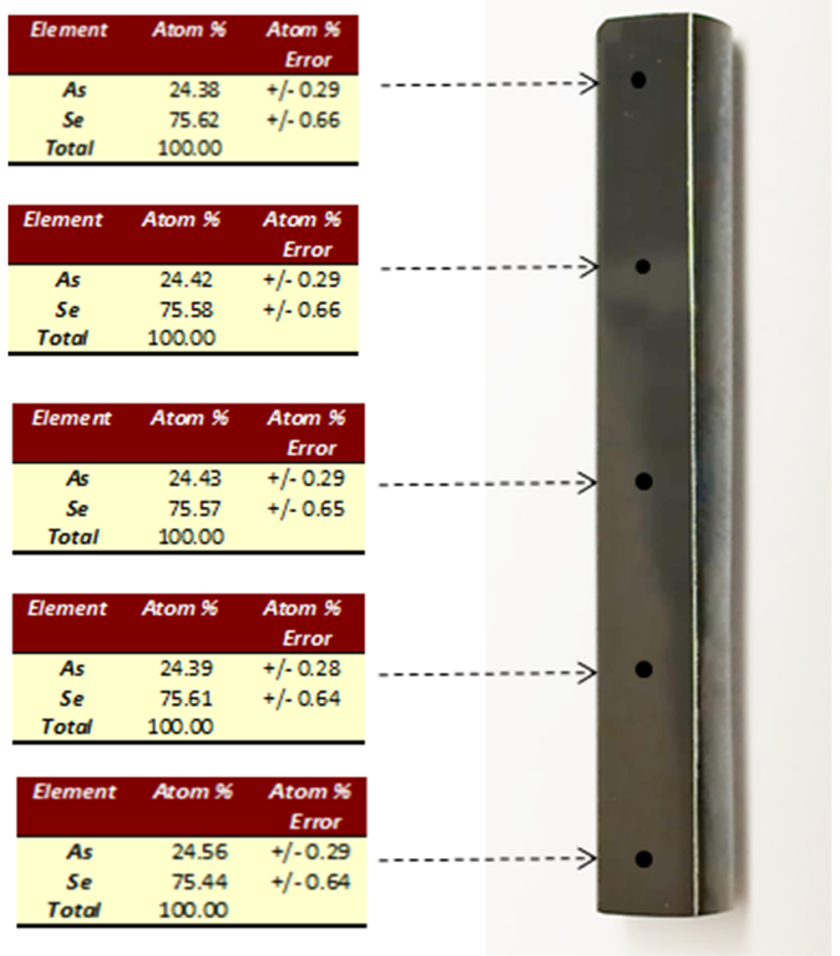

FIG. 2. Quantitative compositional analysis by EDS on five points along an $\mathrm{As}_{25} \mathrm{Se}_{75}$ glass rod produced by melt-rocking. Compositional fluctuations along the rod are well within the experimental error, testifying to the chemical homogeneity of the glass. 

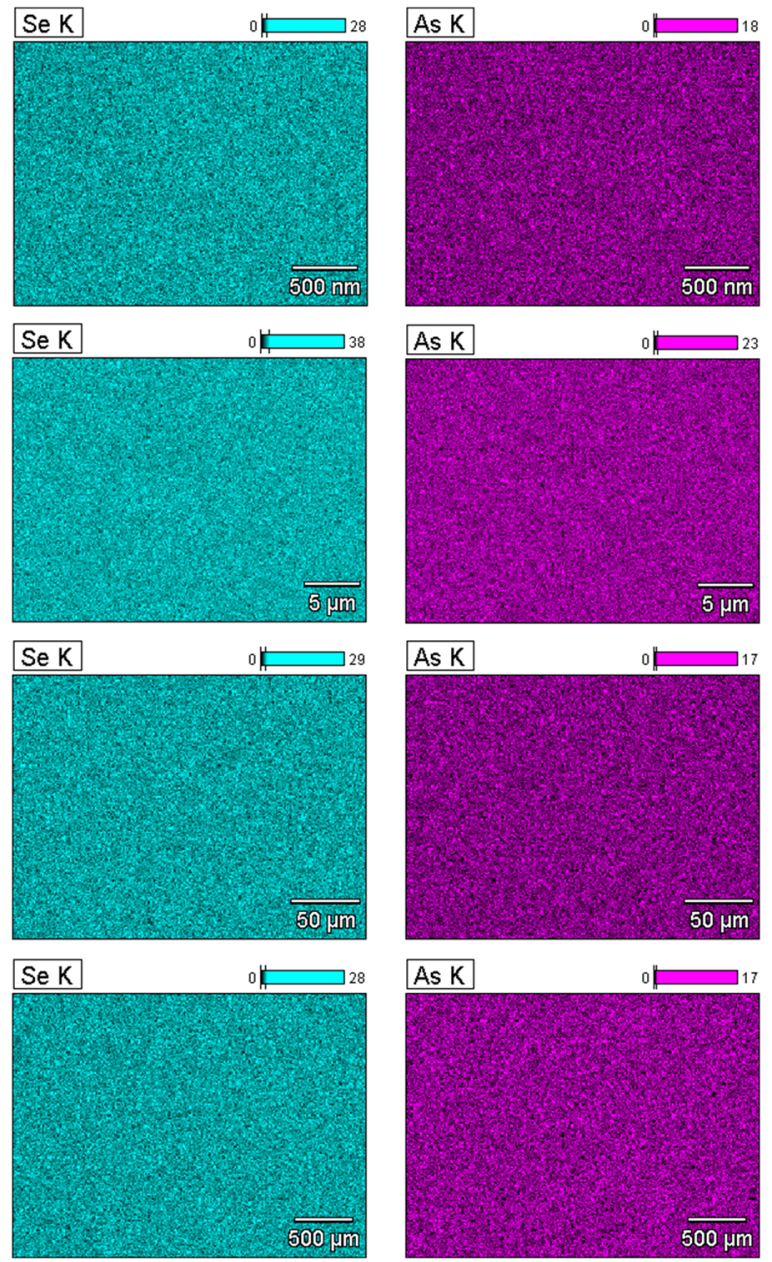

FIG. 3. EDS imaging of an $\mathrm{As}_{25} \mathrm{Se}_{75}$ glass over 4 orders of magnitude in length scale. The Se and As maps demonstrate that the glass is chemically homogeneous at every length scale. The compositional average over each map is also identical at each length scale.

\section{B. Comparison of glasses produced statically and by mechanical agitation}

The properties of $\mathrm{Ge}_{22} \mathrm{Se}_{78}$ glasses produced by meltrocking for $34 \mathrm{~h}$ and $192 \mathrm{~h}$ have been previously measured by Li et $a l .{ }^{42}$ It was found that glasses subjected to extensive homogenization time up to 8 days did not exhibit significant difference in structure or calorimetric properties in comparison to glasses subjected to shorter synthesis time. In order to further investigate a possible difference between glasses synthesized statically and through mechanical agitation we have reproduced strictly the static synthesis method of Bhosle et al. ${ }^{23}$ and compared it with the standard meltrocking method. The two glasses were compared by measuring their densities as it has been previously suggested that this physical property is highly sensitive to homogenization. ${ }^{24-26}$ The densities of the $\mathrm{GeSe}_{4}$ samples produced statically and by melt-rocking are similar within the measurement error with $4.336(3)$ and $4.331(3) \mathrm{g} / \mathrm{cm}^{3}$ for the rocked and static samples, respectively. These values are compared with literature data in Fig. 4. 20,46-55 Our values are in line with the previously reported densities for glasses produced by mechanical agitation of the melt. However, they distinctly depart from the density value of the glass produced statically by Bhosle et al. ${ }^{24}$ Zeidler et al..$^{20}$ previously pointed out that Ge-Se glasses produced following the method of Bhosle et al. exhibit a systematic mismatch in physical properties compared to that generally reported in the literature. It was previously suggested that this discrepancy may be due to the difference in glass preparation and the resulting difference in homogeneity. ${ }^{24-26}$ However, the present results establish that this is not the case. $\mathrm{GeSe}_{4}$ glasses prepared with the same starting elements exhibit identical properties irrespective of the preparation method, as shown in Fig. 4. These findings are consistent with those of Li et al. ${ }^{42}$

Another possibility for the discrepancy in physical properties may be the presence of water or other impurities in the glass. Indeed, it was stated in Ref. 43 that dryness affects the glass properties and furthermore, the density of glasses designated as "wet" and "dry" was shown to diverge in Refs. 24-26, although no spectroscopic or other quantitative measure of water content was provided to support that claim. In order to test this possibility, we measured the density of an ultra-high purity $\mathrm{GeSe}_{4}$ glass used to fabricate low-loss optical fibers. This glass constitutes the state-of-the-art in glass purity and currently holds the record for lowest optical attenuations in $\mathrm{GeSe}_{4} \cdot{ }^{56}$ It is entirely devoid of water as shown in the attenuation curve of Ref. 56. The molar volume of this glass was measured using the remaining part of the preform after fiber drawing. Its value is compared with literature data in Fig. $5 .^{24,46,47,50,57}$ It is found that the molar volume of the ultra-high purity glass is in excellent agreement with general literature values. However, the molar volumes reported by Bhosle et al. are not in quantitative agreement and are systematically overestimated. At this stage, it is unknown why the values of Bhosle et al. systematically deviate from the rest of the literature but it can be concluded that it is not related to structural homogeneity or water content. As previously pointed out by Zeidler et al., ${ }^{20}$ the values of molar volume attributed to Mahadevan et al. in Ref. 26 were incorrectly copied from Ref. 50. Here we further note that the values of molar volume attributed to Mahadevan et al. in Refs. 24 and 25 also correspond to the incorrectly copied data of Ref. 50 and were incorrectly referenced to Ref. 57. To the best of our knowledge, the values of Bhosle et al. do not match any published data in contrast to previous claims. ${ }^{24-26}$

\section{DISCUSSION}

\section{A. Mass transport in As-Se melts}

\section{Self-diffusion}

During the synthesis of an As-Se glass near $700^{\circ} \mathrm{C}$, arsenic is solid while selenium is liquid. Solid arsenic therefore dissolves in liquid selenium which has a viscosity near that 


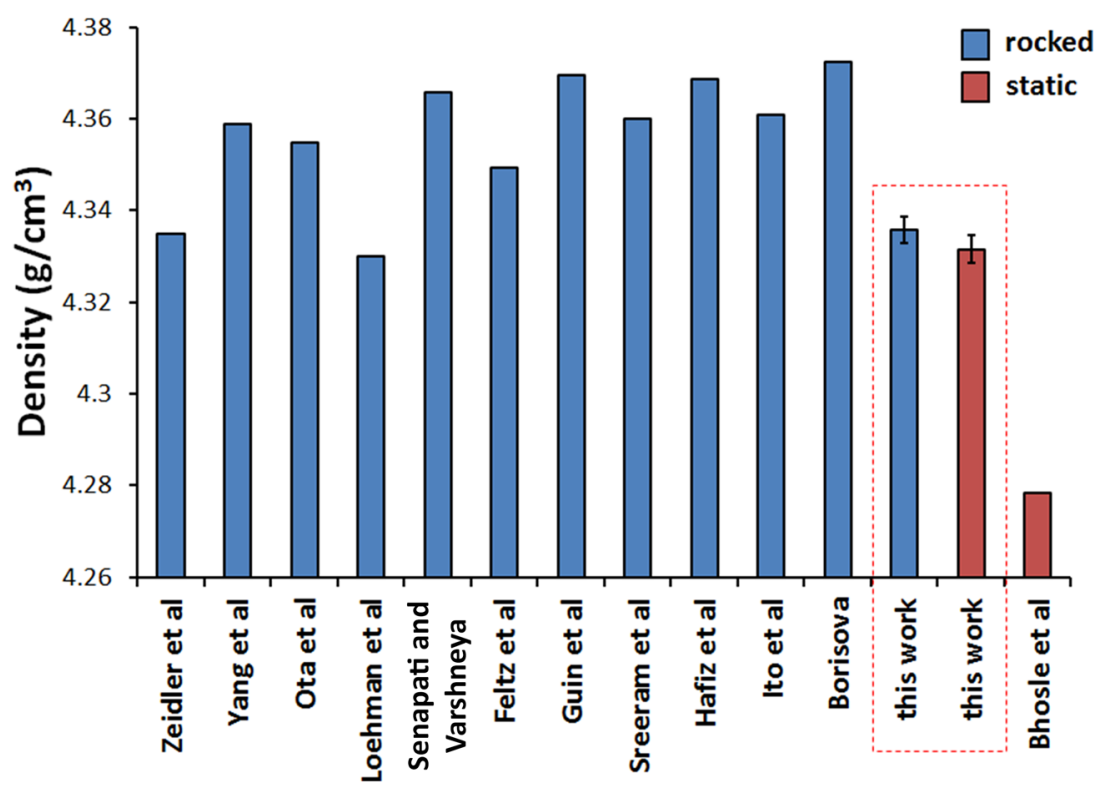

FIG. 4. Density of $\mathrm{GeSe}_{4}$ glasses prepared by mechanical agitation (blue) and by static heating (red). The glasses prepared by the two methods in the present study do not show an experimentally significant difference in density. On the other hand, the value reported by Bhosle et al. ${ }^{24}$ notably departs from the general literature. Data obtained from Zeidler et al., 20 Yang et al., ${ }^{46}$ Ota et al., 47 Loehman et al., 48 Senapati and Varshneya, ${ }^{49}$ Feltz et al., ${ }^{50}$ Guin et al., ${ }^{51}$ Sreeram et al., ${ }^{52}$ Hafiz et al., ${ }^{53}$ Ito et al., 54 and Borisova. 55 of water at $700{ }^{\circ} \mathrm{C} .{ }^{58,59}$ It is a basic staple of mass transport theories that forced convection facilitates the dissolution process by rejuvenating the surface concentration, thereby lowering the chemical potential at the solid-liquid interface and speeding the dissolution process. The result is identical to that of natural diffusion, but agitation by stirring considerably speeds up the process. The same principle applies to rocking an As-Se chalcogenide glass melt. As shown in Fig. 3, EDS confirms homogeneity at every scale down to the

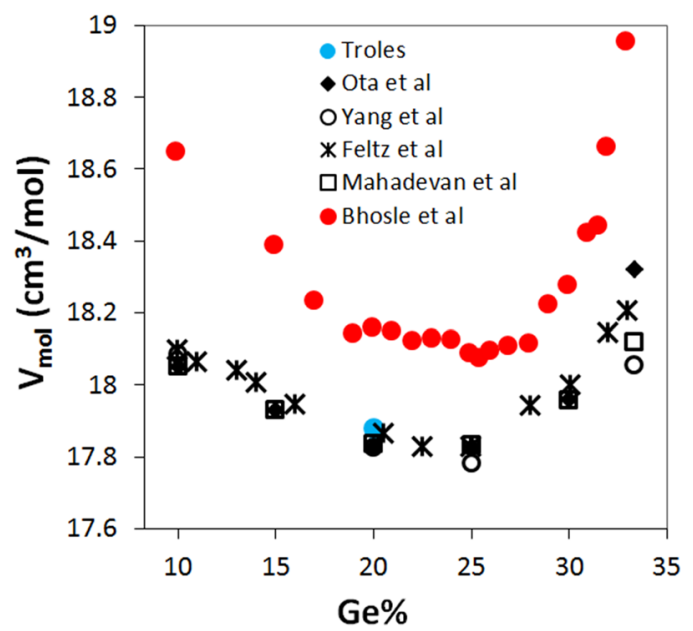

FIG. 5. Molar volume of Ge-Se glasses as a function of composition. Literature data are compared with the value of the ultra-high purity glass produced by Troles et al. ${ }^{56}$ While most literature data are in good agreement, the values of Bhosle et al. systematically deviate. This could be attributed to the presence of impurities such as water. resolution of the technique $(\sim \mu \mathrm{m})$. The existence of inhomogeneity at a sub-micron scale could be hypothesized; however, it can be easily shown that self-diffusion would proceed within seconds at that length scale. A rough estimate of the diffusion length can be derived using the Stokes-Einstein equation

$$
\mathrm{D}=\frac{k_{\mathrm{B}} \mathrm{T}}{6 \pi \eta r}
$$

where $\mathrm{D}$ is the diffusion coefficient, $k_{\mathrm{B}}$ is the Boltzmann constant, $\mathrm{T}$ is the temperature, $\eta$ is the viscosity, and $r$ is the atomic radius taken as $1.2 \AA$. Two stages can be considered during processing of an As-Se glass such as $\mathrm{As}_{25} \mathrm{Se}_{75}$. Here we use available viscosity data for $\mathrm{Se}$ and $\mathrm{As}_{2} \mathrm{Se}_{3}$ to estimate diffusion during the dissolution process. In the first stage at the onset of the synthesis, arsenic dissolves in pure selenium. Based on available viscosity data for Se, ${ }^{58,59}$ the diffusion coefficient of an arsenic atom in the selenium melt would be $\mathrm{D}=1.5 \times 10^{-5} \mathrm{~cm}^{2} / \mathrm{s}$ at $700{ }^{\circ} \mathrm{C}$. For isotropic diffusion, the mean square displacement is $l=\sqrt{6 \mathrm{Dt}}$ so that the diffusion length over $1 \mathrm{~s}$ would be $\sim 100 \mu \mathrm{m}$. At the end of the synthesis, the viscosity of $\mathrm{As}_{2} \mathrm{Se}_{3}$ at $700{ }^{\circ} \mathrm{C}$ given by Churbanov $^{60}$ yields a diffusion coefficient $\mathrm{D}=1.2 \times 10^{-6} \mathrm{~cm}^{2} / \mathrm{s}$ and a diffusion length of $\sim 30 \mu \mathrm{m}$. In either case, this length is far larger than the spatial resolution of the EDS map and therefore confirms that the glass is indeed homogeneous at all length scales.

\section{Viscous flow and fragility}

Several studies have previously suggested that homogenization could not be achieved by melt-rocking due to the high viscosity of the melt. ${ }^{26-28}$ These conclusions were drawn from estimates of the high-temperature viscosity of chalcogenide melts using the MYEGA equation ${ }^{61}$ 


$$
\begin{aligned}
\log \eta(\mathrm{T})= & \log \eta_{\infty}+\left(12-\log \eta_{\infty}\right) \frac{\mathrm{T}_{g}}{\mathrm{~T}} \\
& \times \exp \left[\left(\frac{m}{12-\log \eta_{\infty}}-1\right)\left(\frac{\mathrm{T}_{g}}{\mathrm{~T}}-1\right)\right],
\end{aligned}
$$

where $\log \eta_{\infty}=-5 \mathrm{~Pa} \mathrm{~s},{ }^{62,63} \mathrm{~T}_{g}$ is the temperature, where $\eta=10^{12} \mathrm{~Pa} \mathrm{~s}$, and the fragility index $m$ is obtained from the activation energy $E_{a}$ according to the following equation:

$$
m=\frac{E_{a}}{\mathrm{RT}_{g} \ln 10} .
$$

Unfortunately, these estimates deviate from the measured values by about three orders of magnitude. The source of that mismatch lies in the underestimated values of the activation energy $E_{a}$ derived by calorimetry in the study of Ravindren et al. ${ }^{27}$ In Fig. 6, we use the MYEGA equation (1) to predict the viscosity temperature dependence of $\mathrm{As}_{2} \mathrm{Se}_{3}$ using both the activation energy $E_{a}$ derived by Ravindren et al. ${ }^{27}$ and that derived by Yang et al. ${ }^{64}$ yielding a fragility index $m=23.3$ and $m=39.4$, respectively. The temperature, where $\eta=10^{12} \mathrm{~Pa} \mathrm{~s}$, is $443 \mathrm{~K}$ based on Ref. 29. The predicted viscosity is compared with published data from multiple authors. ${ }^{29,35,60,62,65}$

The viscosity derived from Yang et al. ${ }^{64}$ shows an excellent fit with literature data. On the other hand, the viscosity derived by Ravindren et al. ${ }^{27}$ is largely overestimated and close to that of silica, the strongest known glass-former. In particular, the viscosity value at $700{ }^{\circ} \mathrm{C}$ estimated by Ravindren et al. is $\eta>20 \mathrm{~Pa} \mathrm{~s}$, which would be equivalent to that of ketchup

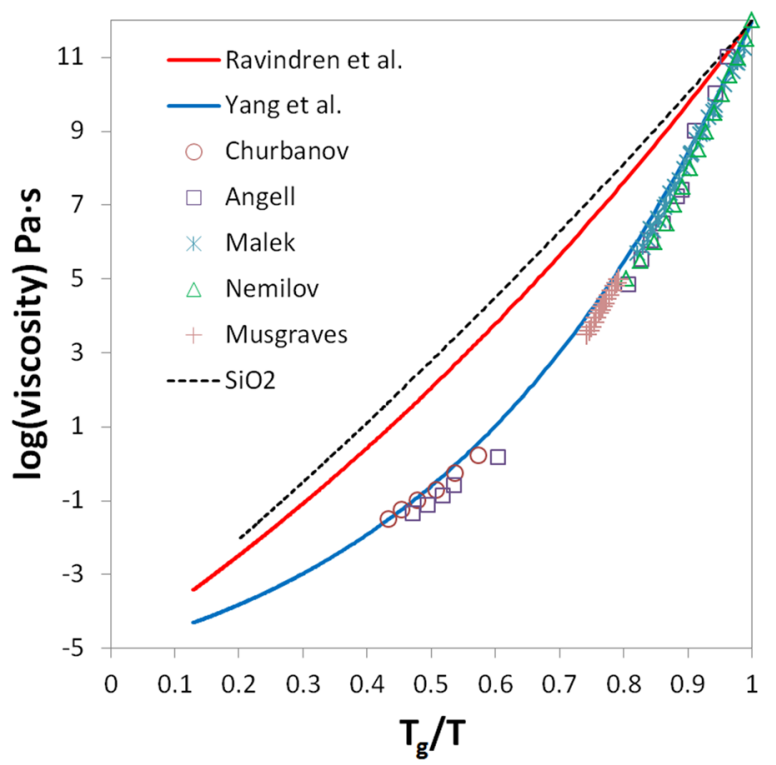

FIG. 6. Fragility plot for $\mathrm{As}_{2} \mathrm{Se}_{3}$. The red curve is derived from the MYEGA equation using the activation energy of Ravindren et al., ${ }^{27}$ and the blue curve is from that of Yang et al. ${ }^{64}$ Experimental viscosity data are from Churbanov, ${ }^{60}$ Angell, ${ }^{62}$ Malek, ${ }^{65}$ Nemilov, ${ }^{29}$ and Musgraves. ${ }^{35}$ High temperature values were obtained by oscillating cup viscometry. at room temperature. Experimentalists familiar with chalcogenide melt synthesis would instantaneously recognize that this is not a realistic value.

Overall, the results of Fig. 6 indicate that the viscous properties of $\mathrm{As}_{2} \mathrm{Se}_{3}$ glasses produced by static heating for extensive periods of time by Ravindren et $a .^{27}$ are not in quantitative agreement with general literature values. This mismatch in viscous properties is reminiscent of the mismatch in other physical properties discussed in Sec. III B and Ref. 20 for Ge-Se glasses. While the origin of this systematic mismatch is currently unknown, exposure to extreme temperatures for such extensive time periods (up to 17 days) could lead to the introduction of a significant concentration of impurities in the glass, especially if low-OH quartz tubes are not used for the synthesis. This may account for the systematic deviation in physical behavior observed in Refs. 23-28 but without further investigation this is only a speculation.

\section{B. Relevance to technological application of chalcogenide glasses}

One of the main technological applications of chalcogenide glasses involves the design of advanced infrared optical elements. ${ }^{1,2}$ In these applications, the chemical homogeneity of the glass is of uttermost importance as it is crucial to the fabrication process as well as the performance of the final product. Much effort has therefore been devoted to optimizing and monitoring the glass homogeneity both at the laboratory and industrial scale.

\section{Photonic crystal fibers}

The principle of photonic crystal fibers is based on controlling the effective index of a microstructured cladding in order to achieve light confinement (see inset of Fig. 7). Adequate manipulation of the effective refractive index requires rigorous control of the linear index and cladding geometry along the fiber length. In this respect, exquisite control of compositional homogeneity is essential as it would affect both the linear refractive index of the glass and the ability to maintain a regular geometry during drawing. The sensitivity of the refractive index on compositional fluctuations is well established as it is the basis for light confinement in core/clad fibers. Indeed, a compositional mismatch of only a few percent is typically introduced between the core and clad glass to achieve single mode guiding. ${ }^{66}$ Hence, any uncontrolled compositional fluctuation would immediately compromise the guiding properties and lead to high optical losses. The low optical losses reported in Fig. 7 therefore testify to the compositional homogeneity of the glass. But maybe more importantly, the glass viscosity is also highly dependent on composition and would affect both the $\mathrm{T}_{g}$ and fragility of the melt. Hence, any compositional fluctuation in the preform of a photonic crystal fiber would lead to inevitable distortion of the cladding geometry during the delicate fiber drawing process. In turn, this would compromise the guiding properties. The highly regular geometry and low optical loss of the photonic 


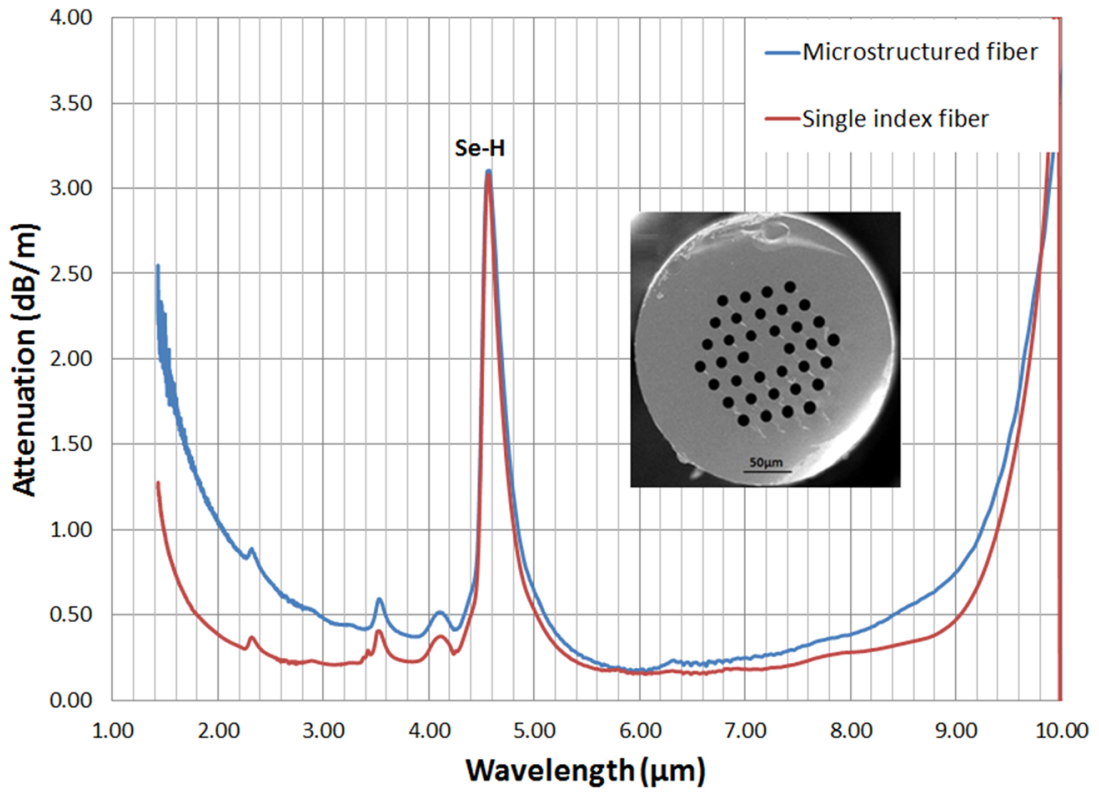

FIG. 7. Optical attenuation of a photonic crystal fiber and single index fiber made of high purity $\mathrm{As}_{38} \mathrm{Se}_{62}$ following the method described in Ref. 1. Optical losses as low as $0.13 \mathrm{~dB} / \mathrm{m}$ at $6 \mu \mathrm{m}$ testify to the compositional homogeneity of the glass.

crystal fiber shown in Fig. 7 therefore also testify to the high homogeneity of the constitutive glass.

\section{Industrial production of molded lenses}

While the sample preparations discussed above dealt with the production of laboratory size samples (typically 5-20 g), industrial glasses on the kilogram scale are also produced through the same melt-rocking process (Fig. 8).2,6

Applications such as thermal imaging involve the design of precision lenses such as spherical, aspherical, and diffractive lenses. ${ }^{2}$ Effective operation of these advanced optical systems requires lenses with an extremely homogeneous and reproducible refractive index in the mid-infrared. For this reason, commercial distributors of chalcogenide lenses have developed optimized procedures for melt homogenization. These procedures must be completed within short time-frames compatible with commercial production and involve mechanical agitation for fast homogenization. In order to guaranty the quality of the products, the refractive index of the glass is also monitored within batches as well as between batches. The reproducibility of a commercial $\mathrm{Ge}_{22} \mathrm{As}_{20} \mathrm{Se}_{58}$ glass produced over 15 years is depicted in Fig. 8. The variation in refractive index between batches is $\sim \Delta n=0.0002$ which is

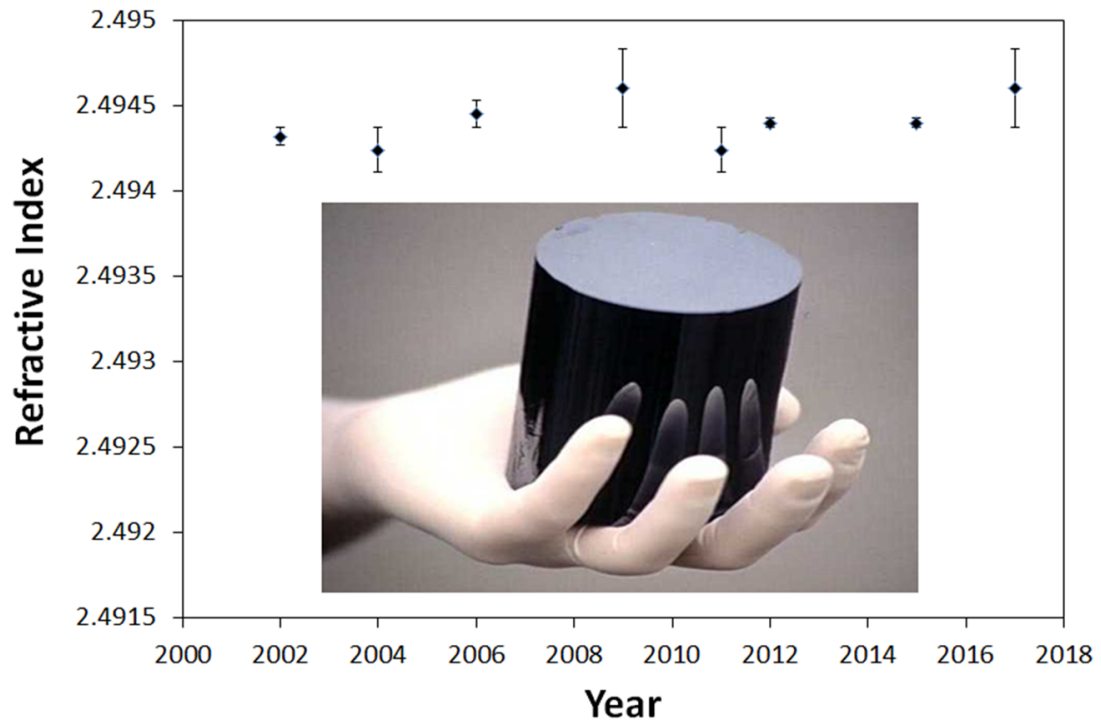

FIG. 8. Batch dependence of the refractive index of the GASIR ${ }^{\circledR}$ glass produced by a Umicore IR glass over 15 years. The reproducibility of the glass refractive index is within the accuracy of measurement bench $\Delta n=2 \times 10^{-4}$. The refractive index was measured at $10 \mu \mathrm{m}$. Inset: A large diameter chalcogenide glass cylinder such as that used for the industrial production of molded lenses. 
within the limit of accuracy of the prism coupling technique. For comparison, a $2 \%$ change in composition in AsSeS glass leads to a change in index $\Delta n=0.15$. $^{67}$ These results indicate that mechanical agitation is an effective homogenization procedure not only for laboratory scale samples but also for kilogram size industrial batches.

\section{CONCLUSION}

The chemical and structural homogeneity of a selenide glass synthesized by mechanical agitation in a rocking furnace was investigated by EDS and Raman spectroscopy. Both EDS and Raman spectroscopy confirm the macroscopic compositional homogeneity along the entire length of the $\mathrm{As}_{25} \mathrm{Se}_{75}$ glass rod prepared by melt-rocking over $10 \mathrm{~h}$. Moreover, EDS imaging at scales ranging over four orders of magnitude demonstrates homogeneity at all length down to the submicron scale. Calculations of the diffusion coefficient based on the Stokes-Einstein equation and experimental viscosity data indicate that the diffusion length is far larger than the resolution of the EDS technique, thereby confirming that the glass is homogeneous at all length scales. In order to investigate the systematic mismatch in physical properties reported in the literature for glasses produced by extended static synthesis, two $\mathrm{GeSe}_{4}$ glasses were produced under identical conditions except for the homogenization step. No difference in physical properties is found between the two glasses. An excellent match in physical properties is also found with an ultrahigh purity $\mathrm{GeSe}_{4}$ glass. The systematic mismatch in physical properties between glasses produced in Refs. 23-28 and the general literature is currently unknown, but the present results demonstrate that it is not the result of homogeneity or dryness, as previously suggested.

\section{ACKNOWLEDGMENTS}

P.L. acknowledges financial support from NSF-DMR under Grant No. 1832817.

\section{REFERENCES}

'J. Troles, Q. Coulombier, G. Canat, M. Duhant, W. Renard, P. Toupin, L. Calvez, G. Renversez, F. Smektala, M. El Amraoui, J. L. Adam, T. Chartier, D. Mechin, and L. Brilland, "Low loss microstructured chalcogenide fibers for large nonlinear effects at 1995 nm," Opt. Express 18, 26647-26654 (2010). ${ }^{2}$ X. H. Zhang, Y. Guimond, and Y. Bellec, "Production of complex chalcogenide glass optics by molding for thermal imaging," J. Non-Cryst. Solids 326-327, 519-523 (2003).

${ }^{3}$ F. Verger, V. Nazabal, F. Colas, P. Nemec, C. Cardinaud, E. Baudet, R. Chahal, E. Rinnert, K. Boukerma, I. Peron, S. Deputier, M. Guilloux-Viry, J. P. Guin, H. Lhermite, A. Moreac, C. Compere, and B. Bureau, "RF sputtered amorphous chalcogenide thin films for surface enhanced infrared absorption spectroscopy," Opt. Mater. Express 3, 2112-2131 (2013).

${ }^{4} \mathrm{M}$. Wuttig and N. Yamada, "Phase-change materials for rewriteable data storage," Nat. Mater. 6, 824-832 (2007).

${ }^{5}$ L. Li, H. Lin, S. Qiao, Y. Zou, S. Danto, K. Richardson, J. D. Musgraves, N. Lu, and J. Hu, "Integrated flexible chalcogenide glass photonic devices," Nat. Photonics 8, 643-649 (2014).

${ }^{6}$ Y. M. Guimond and Y. Bellec, "High-precision IR molded lenses," Proc. SPIE 5252, 103-110 (2004).
${ }^{7}$ C. R. Petersen, R. D. Engelsholm, C. Markos, L. Brilland, C. Caillaud, J. Trolès, and O. Bang, "Increased mid-infrared supercontinuum bandwidth and average power by tapering large-mode-area chalcogenide photonic crystal fibers," Opt. Express 25, 15336-15348 (2017).

${ }^{8}$ S. Cui, R. Chahal, Y. Shpotyuk, C. Boussard, J. Lucas, F. Charpentier, H. Tariel, O. Loreal, V. Nazabal, O. Sire, V. Monbet, Z. Yang, P. Lucas, and B. Bureau, "Selenide and telluride glasses for mid-infrared bio-sensing," Proc. SPIE 8938, 893805-1-893805-9 (2014).

${ }^{9}$ C. Lafond, J.-F. Couillard, J.-L. Delarosbil, F. Sylvain, and P. de Sandro, "Recent improvements on mid-IR chalcogenide optical fibers," Proc. SPIE 9070, 90701C-1-90701C-7 (2014).

${ }^{10} \mathrm{~J}$. D. Musgraves, J. McKinley, and P. Wachtel, "IRradiance glass: Technology transfer from university to industry," Springer Ser. Mater. Sci. 224, 39-58 (2016).

${ }^{11}$ M. F. Thorpe, D. J. Jacobs, M. V. Chubynsky, and J. C. Phillips, "Selforganization in network glasses," J. Non-Cryst. Solids 266-269, 859-866 (2000).

${ }^{12}$ M. Tatsumisago, B. L. Halfpap, J. L. Green, S. M. Lindsay, and C. A. Angell, "Fragility of germanium-arsenic-selenium glass-forming liquids in relation to rigidity percolation, and the Kauzmann paradox," Phys. Rev. Lett. 64, 1549-1552 (1990)

${ }^{13} \mathrm{P}$. K. Gupta and J. C. Mauro, "Composition dependence of glass transition temperature and fragility. I. A topological model incorporating temperature-dependent constraints," J. Chem. Phys. 130, 094503-1094503-8 (2009).

${ }^{14}$ T. Wang, O. Gulbiten, R. Wang, Z. Yang, A. Smith, B. Luther-Davies, and P. Lucas, "Relative contribution of stoichiometry and mean coordination to the fragility of Ge-As-Se glass forming liquids," J. Phys. Chem. B 118, 14361442 (2014)

${ }^{15} \mathrm{X}$. Feng, W. J. Bresser, and P. Boolchand, "Direct evidence for stiffness threshold in chalcogenide glasses," Phys. Rev. Lett. 78, 4422-4425 (1997).

${ }^{16} \mathrm{P}$. Boolchand, X. Feng, and W. J. Bresser, "Rigidity transitions in binary Ge-Se glasses and the intermediate phase," J. Non-Cryst. Solids 293-295, 348-356 (2001).

${ }^{17}$ R. P. Wang, A. Smith, B. Luther-Davies, H. Kokkonen, and I. Jackson, "Observation of two elastic thresholds in $\mathrm{Ge}_{\mathrm{x}} \mathrm{As}_{\mathrm{y}} \mathrm{Se}_{1-\mathrm{x}-\mathrm{y}}$ glasses," J. Appl. Phys. 105, 056109-1-056109-3 (2009).

${ }^{18}$ E. L. Gjersing, S. Sen, and R. E. Youngman, "Mechanistic understanding of the effect of rigidity percolation on structural relaxation in supercooled germanium selenide liquids," Phys. Rev. B: Condens. Matter Mater. Phys. 82, 014203-1-014203-5 (2010).

${ }^{19}$ D. C. Kaseman, I. Hung, Z. Gan, B. Aitken, S. Currie, and S. Sen, "Structural and topological control on physical properties of arsenic selenide glasses," J. Phys. Chem. B 118, 2284-2293 (2014).

${ }^{20}$ A. Zeidler, P. S. Salmon, D. A. J. Whittaker, K. J. Pizzey, and A. C. Hannon, "Topological ordering and viscosity in the glass-forming Ge-Se system: The search for a structural or dynamical signature of the intermediate phase," Front. Mater. 4, 32-1-32-15 (2017).

${ }^{21}$ T. G. Edwards and S. Sen, "Structure and relaxation in germanium selenide glasses and supercooled liquids: A Raman spectroscopic study," J. Phys. Chem. B 115, 4307-4314 (2011).

${ }^{22}$ R. Golovchak, H. Jain, O. Shpotyuk, A. Kozdras, A. Saiter, and J. M. Saiter, "Experimental verification of the reversibility window concept in binary AsSe glasses subjected to a long-term physical aging," Phys. Rev. B: Condens. Matter 78, 014202-1-014202-6 (2008).

${ }^{23}$ S. Bhosle, K. Gunasekera, P. Boolchand, and M. Micoulaut, "Melt homogenization and self-organization in chalcogenides. Part I," Int. J. Appl. Glass Sci. 3, 189-204 (2012).

${ }^{24}$ S. Bhosle, K. Gunasekera, P. Boolchand, and M. Micoulaut, "Melt homogenization and self-organization in chalcogenides. Part II," Int. J. Appl. Glass Sci. 3, 205-220 (2012).

${ }^{25}$ S. Bhosle, K. Gunasekera, P. Chen, P. Boolchand, M. Micoulaut, and C. Massobrio, "Meeting experimental challenges to physics of network glasses: Assessing the role of sample homogeneity," Solid State Commun. 151, 1851-1855 (2011). 
${ }^{26} \mathrm{R}$. Bhageria, K. Gunasekera, P. Boolchand, and M. Micoulaut, "Fragility and molar volumes of non-stoichiometric chalcogenides: The crucial role of melt/glass homogenization," Phys. Status Solidi B 251, 1322-1329 (2014).

${ }^{27}$ S. Ravindren, K. Gunasekera, Z. Tucker, A. Diebold, P. Boolchand, and M. Micoulaut, "Crucial effect of melt homogenization on the fragility of non-stoichiometric chalcogenides," J. Chem. Phys. 140, 134501 (2014).

${ }^{28} \mathrm{~K}$. Gunasekera, S. Bhosle, P. Boolchand, and M. Micoulaut, "Superstrong nature of covalently bonded glass-forming liquids at select compositions," J. Chem. Phys. 139, 164511-1-164511-9 (2013).

${ }^{29} \mathrm{~S}$. V. Nemilov and G. T. Petrovskii, "Viscosity of oxygen-free vitrified systems. II. Study of the viscosity of glasses in the selenium-arsenic system," Zh. Prikl. Khim. (S.-Peterburg, Russ. Fed.) 36, 977-981 (1963).

${ }^{30}$ M. F. Churbanov, V. S. Shiryaev, I. V. Skripachev, G. E. Snopatin, V. G. Pimenov, S. V. Smetanin, R. M. Shaposhnikov, I. E. Fadin, Y. N. Pyrkov, and V. G. Plotnichenko, "High-purity $\mathrm{As}_{2} \mathrm{~S}_{1.5} \mathrm{Se}_{1.5}$ glass optical fibers," Inorg. Mater. 38, 193-197 (2002).

${ }^{31} \mathrm{~K}$. Tanaka, "Structural phase transitions in chalcogenide glasses," Phys. Rev. B: Condens. Matter 39, 1270-1279 (1989).

${ }^{32}$ S. Onari, O. Sugino, M. Kato, and T. Arai, "Far infrared optical properties of amorphous arsenic-selenium system," Jpn. J. Appl. Phys., Part 1 21, 418-423 (1982).

${ }^{33}$ D. C. Kaseman, I. Hung, Z. Gan, and S. Sen, "Observation of a continuous random network structure in $\mathrm{Ge}_{(\mathrm{x})} \mathrm{Se}_{(100-\mathrm{x})}$ glasses: Results from highresolution ${ }^{77}$ Se MATPASS/CPMG NMR spectroscopy," J. Phys. Chem. B 117, 949-954 (2013).

${ }^{34}$ M. Deschamps, C. Roiland, B. Bureau, G. Yang, P. L. Le, and D. Massiot, " ${ }^{77} \mathrm{Se}$ solid-state NMR investigations on $\mathrm{As}_{\mathrm{x}} \mathrm{Se}_{1-\mathrm{x}}$ glasses using CPMG acquisition under MAS," Solid State Nucl. Magn. Reson. 40, 72-77 (2011).

35J. D. Musgraves, P. Wachtel, S. Novak, J. Wilkinson, and K. Richardson, "Composition dependence of the viscosity and other physical properties in the arsenic selenide glass system," J. Appl. Phys. 110, 063503-1-063503-6 (2011).

${ }^{36}$ V. K. Rai, C. B. de Araujo, Y. Ledemi, B. Bureau, M. Poulain, X. H. Zhang, and Y. Messaddeq, "Frequency upconversion in a $\mathrm{Pr}^{3+}$ doped chalcogenide glass containing silver nanoparticles," J. Appl. Phys. 103, 103526-1-103526-4 (2008).

${ }^{37}$ M. A. Afifi, H. H. Labib, M. H. El-Fazary, and M. Fadel, "Electrical and thermal properties of chalcogenide glass system selenium-germaniumantimony $\left(\mathrm{Se}_{75} \mathrm{Ge}_{25-\mathrm{x}} \mathrm{Sb}_{\mathrm{x}}\right.$ )," Appl. Phys. A: Solids Surf. 55, 167-169 (1992).

${ }^{38}$ R. P. Wang, A. Smith, A. Prasad, D. Y. Choi, and B. Luther-Davies, "Raman spectra of $\mathrm{Ge}_{\mathrm{x}} \mathrm{As}_{\mathrm{y}} \mathrm{Se}_{1-\mathrm{x}-\mathrm{y}}$ glasses," J. Appl. Phys. 106, 043520-1-043520-4 (2009).

${ }^{39}$ Y. Guimond, Y. Bellec, and K. Rogers, "A new moldable infrared glass for thermal imaging and low cost sensing," Proc. SPIE 6542, 654225-1-654225-6 (2007).

${ }^{40} \mathrm{~J}$. Franks, K. Rogers, and Y. Guimond, "Optical and thermo mechanical properties of infrared glasses," Proc. SPIE 6940, 69400P-1-69400P-8 (2008).

${ }^{41}$ A. S. Borshchevskii and D. N. Tret'yakov, "Application of vibrational mixing to the synthesis of semiconductor materials," Fiz. Tverd. Tela (S.-Peterburg) 1, 1483-1485 (1959).

${ }^{42}$ P. Li, Y. Zhang, Z. Chen, P. Gao, T. Wu, and L.-M. Wang, "Relaxation dynamics in the strong chalcogenide glass-former of $\mathrm{Ge}_{22} \mathrm{Se}_{78}$," Sci. Rep. 7, 40547 (2017).

${ }^{43}$ M. Bauchy, A. Kachmar, and M. Micoulaut, "Structural, dynamic, electronic, and vibrational properties of flexible, intermediate, and stressed rigid As-Se glasses and liquids from first principles molecular dynamics," J. Chem. Phys. 141, 194506-1-194506-9 (2014).

${ }^{44}$ M. Micoulaut, A. Kachmar, M. Bauchy, S. Le Roux, C. Massobrio, and M. Boero, "Structure, topology, rings, and vibrational and electronic properties of $\mathrm{Ge}_{x} \mathrm{Se}_{1-x}$ glasses across the rigidity transition: A numerical study," Phys. Rev. B: Condens. Matter Mater. Phys. 88, 054203-1-054203-3 (2013).

${ }^{45}$ G. Yang, B. Bureau, T. Rouxel, Y. Gueguen, O. Gulbiten, C. Roiland, E. Soignard, J. L. Yarger, J. Troles, J.-C. Sangleboeuf, and P. Lucas, "Correlation between structure and physical properties of chalcogenide glasses in the $\mathrm{As}_{\mathrm{x}} \mathrm{Se}_{1-\mathrm{x}}$ system," Phys. Rev. B: Condens. Matter 82, 195206-1-195206-8 (2010).

${ }^{46}$ G. Yang, Y. Gueguen, J.-C. Sangleboeuf, T. Rouxel, C. Boussard-Pledel, J. Troles, P. Lucas, and B. Bureau, "Physical properties of the $\mathrm{Ge}_{\mathrm{x}} \mathrm{Se}_{1-\mathrm{x}}$ glasses in the $0<\mathrm{x}<0.42$ range in correlation with their structure," $J$. Non-Cryst. Solids 377, 54-59 (2013).

${ }^{47}$ R. Ota, T. Yamate, N. Soga, and M. Kunugi, "Elastic properties of Ge-Se glass under pressure," J. Non-Cryst. Solids 29, 67-76 (1978).

${ }^{48}$ R. E. Loehman, A. J. Armstrong, D. W. Firestone, and R. W. Gould, "Composition and physical properties of amorphous bulk and thin film materials in the system Ge-Se-Te-As," J. Non-Cryst. Solids 8-10, $72-77$ (1972).

${ }^{49} \mathrm{U}$. Senapati and A. K. Varshneya, "Configurational arrangements in chalcogenide glasses: A new perspective on Phillips' constraint theory," J. Non-Cryst. Solids 185, 289-296 (1995).

${ }^{50} \mathrm{~A}$. Feltz, H. Aust, and A. Blayer, "Glass formation and properties of chalcogenide systems XXVI: Permittivity and the structure of glasses $\mathrm{As}_{\mathrm{x}} \mathrm{Se}_{1-\mathrm{x}}$ and $\mathrm{Ge}_{\mathrm{x}} \mathrm{Se}_{1-\mathrm{x}}$, , J. Non-Cryst. Solids 55, 179-190 (1983).

${ }^{51}$ J. P. Guin, T. Rouxel, J. C. Sangleboeuf, I. Melscoet, and J. Lucas, "Hardness, toughness, and scratchability of germanium-selenium chalcogenide glasses," J. Am. Ceram. Soc. 85, 1545 (2002).

${ }^{52}$ A. N. Sreeram, A. K. Varshneya, and D. R. Swiler, "Molar volume and elastic properties of multicomponent chalcogenide glasses," J. Non-Cryst. Solids 128, 294-309 (1991).

${ }^{53}$ M. M. Hafiz, F. H. Hammad, and N. A. El-Kabany, "Short- and mediumrange order in Se-Ge glassy systems (I) effect of composition," Physica B 183, 392-398 (1993).

${ }^{54} \mathrm{Y}$. Ito, S. Kashida, and K. Murase, "Elastic constants of the chalcogenides glasses $\left(\mathrm{Ge}_{\mathrm{x}} \mathrm{Se}_{1-\mathrm{x}^{\prime}}, \mathrm{As}_{\mathrm{y}} \mathrm{Se}_{1-\mathrm{y}}\right.$ and $\left.\mathrm{Ge}_{23 z} \mathrm{As}_{13 \mathrm{z}} \mathrm{Se}_{1-\mathrm{z}}\right)$," Solid State Commun. 65, 449-452 (1988).

${ }^{55}$ Z. U. Borisova, Glassy Semiconductors (Plenum Press, 1981).

${ }^{56} \mathrm{~J}$. Troles, V. Shiryaev, M. Churbanov, P. Houizot, L. Brilland, F. Desevedavy, F. Charpentier, T. Pain, G. Snopatin, and J. L. Adam, "GeSe 4 glass fibres with low optical losses in the mid-IR," Opt. Mater. (Amsterdam, Neth.) 32, 212-215 (2009).

${ }^{57}$ S. Mahadevan, A. Giridhar, and A. K. Singh, "Elastic properties of Ge-Sb-Se glasses," J. Non-Cryst. Solids 57, 423-430 (1983).

${ }^{58} \mathrm{~V}$. M. Glazov and O. D. Shchelikov, "Change in short-range order structure in selenium and tellurium melts during heating," Izv. Akad. Nauk SSSR, Neorg. Mater. 10, 202-207 (1974).

${ }^{59}$ M. Fischer and H. Krebs, "Viscosity of chalcogenide melts," Glastech. Ber. 47, 42-51 (1974).

${ }^{60}$ M. F. Churbanov, R. M. Shaposhnikov, I. V. Skripachev, and G. E. Snopatin, "Flow of molten arsenic selenide in a cylindrical channel," Inorg. Mater. 39, $77-81$ (2003).

${ }^{61}$ J. C. Mauro, Y. Yue, A. J. Ellison, P. K. Gupta, and D. C. Allan, "Viscosity of glass-forming liquids," Proc. Natl. Acad. Sci. U. S. A. 106, 19780-19784 (2009). ${ }^{62} \mathrm{~L}$. M. Martinez and C. A. Angell, "A thermodynamic connection to the fragility of glass-forming liquids," Nature (London, U. K.) 410, 663-667 (2001).

${ }^{63} \mathrm{C}$. A. Angell, "Formation of glasses from liquids and biopolymers," Science 267, 1924-1935 (1995).

${ }^{64}$ G. Yang, O. Gulbiten, Y. Gueguen, B. Bureau, J.-C. Sangleboeuf, C. Roiland, E. A. King, and P. Lucas, "Fragile-strong behavior in the $\mathrm{As}_{\mathrm{x}} \mathrm{Se}_{1-\mathrm{x}}$ glass forming system in relation to structural dimensionality," Phys. Rev. B: Condens. Matter 85, 144107-1-144107-8 (2012).

${ }^{65} \mathrm{~J}$. Malek and J. Shanelova, "Structural relaxation of $\mathrm{As}_{2} \mathrm{Se}_{3}$ glass and viscosity of supercooled liquid," J. Non-Cryst. Solids 351, 3458-3467 (2005). ${ }^{66} \mathrm{Z}$. Yang, T. Luo, S. Jiang, J. Geng, and P. Lucas, "Single-mode low-loss optical fibers for long-wave infrared transmission," Opt. Lett. 35, 3360-3362 (2010).

${ }^{67}$ E. Guillevic, X. Zhang, T. Pain, L. Calvez, J.-L. Adam, J. Lucas, M. GuillouxViry, S. Ollivier, and G. Gadret, "Optimization of chalcogenide glass in the As-Se-S system for automotive applications," Opt. Mater. 31, 1688-1692 (2009). 